\title{
HEDGE, REDUÇÃO DE VOLATILIDADE DOS LUCROS E O EFEITO SOBRE O IMPOSTO DE RENDA DAS COMPANHIAS ABERTAS BRASILEIRAS
}

\author{
VALDIR DE JESUS LAMEIRA \\ Doutorando em Administração pelo IAG/PUC-Rio - RJ \\ E-mail: vlameira@uol.com.br
}

\author{
ANTÔNIO CARLOS FIGUEIREDO \\ Prof. Titular do Depto. de Administração - IAG/PUC-Rio - RJ \\ E-mail: figueiredo@iag.puc-rio.br
}

\section{WALTER LEE NESS JR.}

Prof. Dr. do Depto. de Administração - IAG/PUC-Rio - RJ

E-mail: ness@iag.puc-rio.br

\section{RESUMO}

Neste artigo, procurou-se identificar se as companhias abertas brasileiras teriam conseguido benefícios fiscais ao fazer hedge, fato esse derivado de uma expectativa de queda da sua carga tributária (Imposto de Renda a pagar). Com esse objetivo, inicialmente pesquisou-se em que situações haveria possibilidade de geração desse benefício. Após essa revisão, foram estudadas situações em que a companhia tivesse grande volatilidade de seus resultados e os efeitos que o hedge traria no valor do I.R. a ser pago. Assim, pôde-se mensurar o efeito do resultado do hedge na carga tributária dessas companhias nesse período, simulando uma situação teórica para melhor evidenciarem-se os efeitos resultantes dessa prática. Posteriormente, utilizouse uma regressão linear múltipla para relacionar o valor do imposto de renda pago por companhias abertas brasileiras no ano de 2003 com os valores de hedge em 2002 e 2003 e os prejuízos acumulados em 2002. Os resultados são fundamentados em vasta bibliografia referente ao assunto.

Palavras-chave: Hedge; Tributação; Companhias Abertas.

\section{ABSTRACT}

In this article we try to identify if Brazilian public companies hedge in response to tax incentives. With this goal, we first identify in which conditions the hedge causes reductions in tax obligations. Next, we study theoretical situations in which the companies' financial results change from great losses to great profits and we observe the impact in the companies' tax liabilities. Finally, we observe the results of a regression that tries to explain the tax obligations in 2003 in function of the hedge values in 2002, 2003 and the net operational losses in 2002. We conclude that it is possible to hedge in response to tax benefits in some special situations. Our results and conclusions are supported by other studies.

Keywords: Hedge; Taxation; Public Companies. 


\section{INTRODUÇÃO}

Neste artigo, pesquisou-se como objetivo principal se as corporações brasileiras fazem hedge em busca da diminuição de sua carga tributária, entendida como diminuição do seu Imposto de Renda (I.R.) a pagar.

Algumas pesquisas comprovam a existência de benefício fiscal (decorrente da queda da tributação) derivado do fato de as companhias terem feito hedge como evidenciam a pesquisa e os resultados encontrados por Graham e Rogers (2000). Assim, buscouse verificar se as companhias abertas brasileiras que tenham feito hedge para se protegerem do risco de subida da taxa de câmbio e dos juros, nos anos de 2002 e 2003, conseguiram com isso vantagem tributária, diminuindo o valor do imposto de renda que teriam que pagar caso não tivessem feito hedge.

Para isso, simulou-se uma situação em que o hedge pode gerar benefícios em termos de queda dos valores de imposto de renda a serem pagos pela empresa. Para que a companhia experimente significativos ganhos de imposto (em relação aos seus lucros líquidos) é necessário que a empresa alterne resultados de lucros e prejuízos significativamente grandes. Essa volatilidade de resultados ocorre na região de descontinuidade de alíquotas de tributação, o que se demonstrou que provoca a ocorrência de convexidade da taxa e gera a possibilidade de ganhos decorrentes de queda de carga tributária para as empresas.

Após essa simulação procurou-se exemplos de companhias abertas brasileiras que tenham feito hedge nos anos de 2002 e 2003 e buscou-se evidências estatísticas de correlação entre o fato de terem feito hedge e o valor do imposto de renda que pagaram.

Dessa maneira, comprovou-se que existe a possibilidade de queda no I.R. a pagar, para uma amostra de empresas que têm uma política de hedge e que foram expostas a situações de elevada instabilidade cambial e de juros, como a verificada ao longo dos anos de 2002 e 2003, no Brasil.

$O$ artigo se desenvolveu da seguinte forma: na segunda seção foi construído um referencial teórico que serviu de embasamento para essa pesquisa. $\mathrm{Na}$ terceira seção apresentou-se a metodologia utilizada na pesquisa. Na quarta seção foi apresentada uma simulação teórica que demonstra a vantagem tributária de se fazer hedge em momentos de grande volatilidade dos resultados. Na quinta seção evidenciou-se os resultados empíricos obtidos por algumas companhias abertas brasileiras e comprovou-se estatisticamente que existe vantagem em se fazer hedge para diminuir a carga tributária em perí- odos de grande volatilidade de resultados. Na sexta seção são apresentados os resultados, sua análise e as conclusões.

\section{REVISÃO BIBLIOGRÁFICA}

Denomina-se por hedge a operação pela qual se busca a proteção contra o risco da oscilação dos preços de um ou mais ativos. Dessa forma, a operação de hedge promove uma espécie de seguro contra oscilações de preços que possam prejudicar o desempenho da empresa observado em seu lucro líquido e fluxo de caixa.

Em um mercado perfeito, o hedge com instrumentos financeiros não deveria possibilitar ganhos às organizações e, portanto, as empresas não deveriam fazê-lo, pois não agregariam valor por meio dessa prática. Isto se fundamenta no fato de que em um mercado perfeito não existem desequilíbrios na formação dos preços dos ativos ao longo do tempo, pois os agentes são eficientes e não permitiriam o aparecimento de oportunidades de arbitragem, além do fato de que todas as informações futuras a respeito dos ativos já estariam ajustadas aos seus valores presentes, e dessa forma não se conseguiria promover ganhos de valor em se fazer hedge. No entanto, essa não é a realidade vivenciada nos mercados financeiros, especialmente nos emergentes, em que existem períodos de grande instabilidade que proporcionam desequilíbrios na formação dos preços dos ativos, como foi exemplo a taxa de câmbio ao final do ano de 2002.

Contudo, nos mercados existentes as empresas podem buscar diversas motivações para o uso de derivativos. Apesar de Guay e Kothari (2003) concluírem que se faz proporcionalmente pouco hedge nos Estados Unidos, em vista da possível exposição ao risco a que as grandes corporações americanas estão expostas, existem vários artigos que buscam explicar as motivações de se fazer hedge. Essa menor propensão ao hedge por grandes corporações americanas se deve em parte ao hedge natural que têm em vista atuarem em diferentes países com diferentes moedas sendo o dólar o padrão de referência mundial para o comércio. Ammont (1998), Graham e Rogers (2000) e Beber (2001) comprovam a importância de se fazer hedge de modo a aumentar o valor da empresa e ressaltam a importância de se fazer hedge em busca de benefícios fiscais, como uma das razões de se buscar essa proteção contra o risco da oscilação de preços. Com mais ênfase, Judge (2003) destaca a importância de fatores institucionais próprios de cada economia como fator determinante do nível de hedge contratado pelas empresas. 
Dessa forma, Chiech e Rocha (2002) enfatizam a importância de se fazer hedge no Brasil em vista da instabilidade econômica e Figueiredo (2002) evidencia como as empresas e demais investidores podem utilizar os derivativos na prática do dia-a-dia do mercado financeiro. Porém, no Brasil o hedge têm um alto custo pois todas as posições possíveis de serem assumidas no futuro carregam em seus preços o custo da taxa de juros Selic, que é uma das maiores do mundo, em termos reais. Assim, poucas empresas se utilizam do hedge no Brasil e este hedge só se torna eficiente quando ocorre grande volatilidade dos preços dos ativos, como verificamos no final de 2002, quando a taxa de câmbio e depois a taxa Selic subiram muito, e ao longo do ano de 2003 quando as taxas mencionadas retornaram ao patamar que antecedia essa subida. Verifica-se na prática que somente grandes corporações brasileiras têm uma política de hedge definida.

Contudo, a teoria sugere que as empresas podem aumentar seu valor fazendo hedge de forma a administrar eficientemente os riscos relativos aos custos de financiamento, às questões tributárias, aos problemas de sub-investimento ou ainda a problemas ligados a incentivos gerenciais ${ }^{1}$.

A respeito dos custos de financiamento e questões tributárias, a teoria sugere que o gerenciamento de risco pode evitar que a volatilidade do caixa da empresa passe por momentos que provoquem aumento dos seus custos de financiamento em vista do risco de inadimplência ou falência (com efeitos no weighted average cost of capital - wacc). Dessa forma, o gerenciamento eficaz da volatilidade do caixa pode aumentar o valor da empresa.

Outro possível benefício a ser gerado pelo hedge é que ao diminuir o risco do aumento das taxas de financiamento, a empresa pode passar a ter um novo nível ótimo de estrutura de capital e um novo patamar de custo de capital. Com isso a companhia pode obter maiores lucros e viabilizar uma série de projetos adicionais.

Além disso, as empresas podem empreender gerenciamento de risco na busca de minimizarem a volatilidade de seus lucros tributáveis e reduzirem seu nível de impostos. Dessa forma, as empresas podem buscar uma alternativa para a situação de terem prejuízos acumulados e no ano em que alcançam lucros muito altos têm que pagar alto imposto de renda pois não podem compensar a totalidade dos prejuízos anteriores. Caso tivessem tido um lucro médio pequeno nos anos considerados poderiam ter diminuído o valor do imposto de renda que pagaram no ano em que tiveram lucro muito alto.
Algumas operações de hedge que previnam contra uma variação muito grande da taxa de câmbio ou da taxa de juros podem melhorar o desempenho de companhias que apresentem elevado endividamento. Assim, tais empresas podem diminuir suas perdas nos anos em que o câmbio ou os juros tenham uma subida muito forte. Da mesma forma, em anos que as taxas de juros e o câmbio caiam as empresas podem perder valor em vista de terem feito hedge. Porém, na média de 2 anos na qual se verifique uma subida muito forte e depois uma queda muito grande do câmbio ou dos juros, retornando ao mesmo patamar do início do ano anterior, a política de hedge pode contribuir para que o imposto de renda a pagar, calculado sobre o lucro médio, seja menor que a soma dos impostos de renda a pagar dos dois anos, caso a empresa não tivesse feito hedge.

A teoria conduz, inclusive, a um determinado perfil de empresas que estarão mais propensas a fazer hedge com esses objetivos, que serão companhias que apresentem alta alavancagem, dívidas de curto prazo, baixos índices de cobertura para pagamento de dívidas e baixa liquidez.

Smith e Stulz (1985), entre outros, evidenciam os efeitos da convexidade da função de tributação sobre o valor esperado de impostos a serem pagos pelas companhias. No Gráfico 1, a seguir, essa relação fica ainda mais evidente, tendo em vista a aplicação da desigualdade de Jensen, a qual prova, matematicamente, que a média entre dois pontos de uma função convexa é maior que o valor da função nesse ponto.

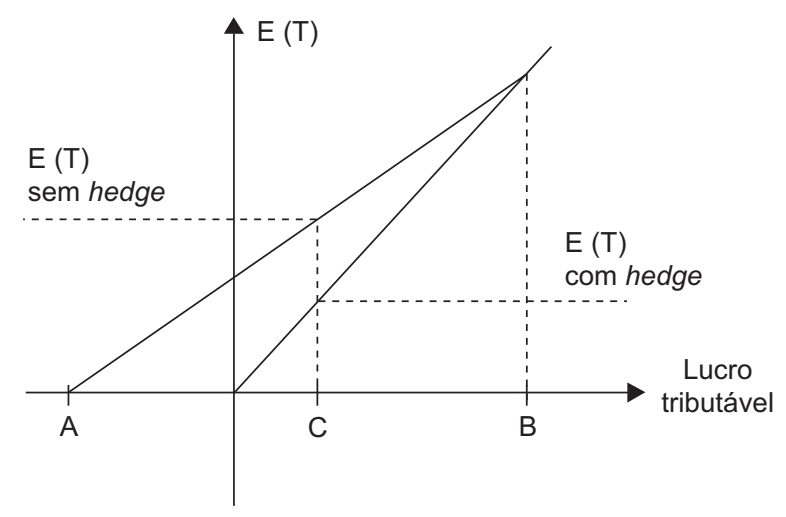

Fonte: Elaborado pelos autores.

\section{Gráfico 1 - Efeitos da convexidade na função tributação}

${ }^{1}$ Bartram, Söhnke M.; Brown, Gregory W.; Fehle, Frank R. - International evidence of financial derivative usage. Site www.ssrn.com, março, 2004. 
Em que:

A - LAIR negativo do exercício T 0;

$B$ - LAIR positivo do exercício T 1;

C - LAIR médio dos exercícios T 0 e T 1;

$\mathrm{E}$ (T) sem hedge - valor esperado de tributação caso a empresa não tenha feito hedge para diminuir a volatilidade de seus lucros;

E (T) com hedge - valor esperado de tributação caso a empresa tenha feito hedge para diminuir a volatilidade de seus lucros.

A partir desse postulado observa-se que empresas que eliminam a volatilidade de seus resultados, que ora são negativos ora positivos, agregam valor ao seu patrimônio em decorrência da queda do valor do imposto sobre seus lucros.

Da mesma forma, se a empresa experimentar funções de tributação côncavas, o hedge de seus lucros faz aumentar o valor da tributação e a queda de valor da companhia.

Graham e Rogers (2000) argumentam que se as empresas tivessem taxas lineares de tributação ao longo de todo o intervalo possível de resultados não existiria a possibilidade de se encontrar incentivo tributário fundamentado na convexidade das funções de tributação. Esse somente não seria o caso se as empresas recebessem do governo uma devolução de imposto caso tivessem tido prejuízo ou se pudessem utilizar imediatamente o valor desse imposto a lhes ser restituído, sem qualquer perda de valor financeiro.

Porém, a legislação tributária brasileira permite que as empresas deduzam somente parte de seus prejuízos ao longo dos exercícios sociais futuros, com limitações inclusive da espécie de lucro a ser compensado com o prejuízo gerado.

$\mathrm{Na}$ teoria, essas limitações devem conduzir as empresas a terem funções de tributação convexas. Assim, inicialmente é possível que as empresas busquem o hedge visando agregar valor, com a redução de suas cargas tributárias, aproveitando-se, para tanto, da convexidade de suas funções de tributação.

Dessa forma, Graham e Rogers construíram uma amostra de 3.232 companhias abertas norte americanas, no sentido de observarem se essas organizações fizeram hedge para aumentar sua capacidade de endividamento ou se buscaram diminuir sua carga tributária, no caso de possuírem funções de tributação convexas.

Para isso, utilizaram uma regressão em 2 estágios de modo a testar a validade das hipóteses mencionadas. Seus resultados mostram que as empresas não fazem hedge diretamente para diminuírem suas cargas tributárias. Contudo, observam que o incentivo do hedge de possibilitar o aumento do endividamento da empresa está diretamente relacionado com a taxa marginal de tributação (variável utilizada por eles para estimar a convexidade da função tributária das empresas), o que demonstra que o incentivo do hedge em aumentar o endividamento ocorre em vista da possibilidade de se deduzirem as despesas financeiras decorrentes desse novo endividamento do lucro tributável a ser auferido no exercício.

Em sua amostra, os pesquisadores verificaram, ainda, que os incentivos decorrentes da exploração da convexidade das funções de tributação por parte das empresas eram relevantes para uma pequena parte das companhias pesquisadas. Além disso, observaram que a existência de prejuízos acumulados diminuía o incentivo de as empresas fazerem hedge em busca de benefícios fiscais, tendo em vista que o valor dos prejuízos acumulados funciona como um fator de diminuição do valor dos lucros tributáveis o que por si só já diminui ou elimina a necessidade de a empresa buscar o hedge em função de pagar menos imposto de renda.

Para testarem a existência do incentivo da queda de imposto a pagar nas empresas que praticaram hedge, os pesquisadores calcularam os ganhos gerados pela queda de tributação que as empresas experimentariam caso a volatilidade de seus lucros caísse. Com isso verificaram uma queda proporcional do imposto a pagar.

Também em Graham e Rogers (2002) observa-se a utilização de uma amostra de companhias sujeitas ao risco de taxas de juros e risco de câmbio no sentido de se verificar se os valores de hedge variavam em função do custo de stress financeiro, em razão do tamanho da firma, das oportunidades de investimento, da oportunidade de a empresa poder se alavancar em maior grau com capital de terceiros ou aproveitar a convexidade da tributação.

No referido estudo, os autores testam a hipótese de que as empresas façam hedge em função da convexidade das suas funções de tributação. Partem da suposição de que essa correlação existe e que seja positiva, assumindo uma nova variável para o teste que é a taxa de convexidade dos tributos. Essa taxa é calculada através da razão entre o valor estimado de queda de impostos a serem pagos pelas empresas para uma queda de $5 \%$ na volatilidade dos lucros das empresas.

Verificou-se, nesse estudo, que o hedge das empresas não é relacionado à estimativa de convexidade das funções de tributação das empresas, pois o ganho possível de ser auferido com o aumento da alavancagem é muito maior que o ganho a ser conseguido com a diminuição de impostos. Portan- 
to, o resultado é que não se verifica forte correlação entre o fato de as empresas buscarem hedge e a existência de convexidade nas taxas de tributação.

Os autores, ainda, dão transparência a uma tabela, que foi incluída como Tabela 1, com resultados de pesquisas sobre o assunto, nas quais foi testada a possibilidade de relacionamento entre a prática de hedge e a convexidade das funções de tributação das empresas. O resultado é resumido na Tabela 1 evidenciada a seguir.

Os autores mencionam, ainda, dois pontos relevantes a respeito do resultado da pesquisa para o teste dessa correlação. Um deles é que as pesquisas posteriores devem se aprofundar na procura de melhores variáveis que possam aferir com maior exatidão a função de convexidade das tributações.

A esse respeito percebe-se que já houve um avanço no uso de uma razão que envolve a queda da tributação e a queda da volatilidade dos lucros das empresas, ou mesmo a estimativa de uma taxa marginal de tributação, em vez da utilização da va- riável prejuízo operacional líquido anteriormente utilizada.

A segunda questão é que existe forte correlação entre a prática de hedge pelas empresas e o aumento da alavancagem financeira de seus patrimônios. Ocorre que essa alavancagem gera uma queda de tributação decorrente da possibilidade de se abaterem do lucro tributável as despesas financeiras relativas ao excesso de endividamento ocorrido em função do hedge. Portanto, pode-se vincular, indiretamente, a política de hedge ao efeito tributário via aumento da possibilidade de alavancagem das firmas, conforme já mencionado. Cabe ressaltar que não é objetivo desta pesquisa o teste de existência dessa relação nas companhias brasileiras no período proposto neste artigo.

Outra pesquisa importante relacionada ao tema é a de Graham e Smith (1998) que investigaram o comportamento da função tributação de 80.000 empresas componentes do Compustat (site americano de informações sobre companhias abertas de todo

Tabela 1 - Resumo de estudos sobre o assunto

\begin{tabular}{|c|c|c|c|c|c|}
\hline Estudo & Método & Amostra & Taxa de convexidade & $\begin{array}{l}\text { Predição do sinal } \\
\text { de correlação }\end{array}$ & Resultado \\
\hline Nance et al. (1993) & Logit & Fortune 500/S\&P 400 & $\begin{array}{l}\text { Valor do Prejuízo } \\
\text { Operacional Líquido }\end{array}$ & + & Não \\
\hline Dolde (1995) & Logit & Fortune 500 & $\begin{array}{l}\text { Valor do Prejuízo } \\
\text { Operacional Líquido }\end{array}$ & + & Não \\
\hline $\begin{array}{l}\text { Berkman e } \\
\text { Bradbury (1996) }\end{array}$ & Tobit & $\begin{array}{c}\text { New Zeland } \\
\text { public companies }\end{array}$ & $\begin{array}{l}\text { Valor do Prejuízo } \\
\text { Operacional Líquido }\end{array}$ & + & Não \\
\hline Mian (1996) & Logit & 3.022 companies & $\begin{array}{l}\text { Valor do Prejuízo } \\
\text { Operacional Líquido }\end{array}$ & + & Não \\
\hline Tufano (1996) & Tobit & Gold mining firms & $\begin{array}{l}\text { Valor do Prejuízo } \\
\text { Operacional Líquido }\end{array}$ & + & Não \\
\hline Geczy et al. (1997) & Logit & Fortune 500 & $\begin{array}{l}\text { Valor do Prejuízo } \\
\text { Operacional Líquido }\end{array}$ & + & Não \\
\hline $\begin{array}{l}\text { Allayannis e } \\
\text { Ofek (1998) }\end{array}$ & Tobit \& Cragg & S\&P 500 & $\begin{array}{l}\text { Valor do Prejuízo } \\
\text { Operacional Líquido }\end{array}$ & + & Não \\
\hline Haushalter (1998) & Tobit \& Cragg & Oil \& gas firms & $\begin{array}{l}\text { Taxa marginal } \\
\text { de tributação }\end{array}$ & + & Não \\
\hline Gay e Nam (1999) & Tobit & $\begin{array}{l}\text { Business Week } \\
1.000 \text { data base }\end{array}$ & $\begin{array}{l}\text { Valor do Prejuízo } \\
\text { Operacional Líquido }\end{array}$ & + & Não \\
\hline $\begin{array}{l}\text { Howton e } \\
\text { Perfect (1999) }\end{array}$ & Tobit & Fortune/ S\& P 500 & $\begin{array}{l}\text { Valor do Prejuízo } \\
\text { Operacional Líquido }\end{array}$ & + & Não \\
\hline $\begin{array}{l}\text { Graham e } \\
\text { Rogers (2000) }\end{array}$ & Tobit \& Cragg & U.S. public companies & $\begin{array}{l}\text { Convexidade das } \\
\text { taxas de tributação }\end{array}$ & + & Não \\
\hline
\end{tabular}


mundo) ao longo do período compreendido entre 1980 e 1994. Assim, inicialmente puderam comprovar que apenas $25 \%$ das funções de tributação são côncavas e que os prejuízos fiscais a compensar são os maiores empecilhos a se buscar o hedge com objetivo de conseguir incentivos fiscais.

Além disso, observaram que uma queda na volatilidade dos lucros tributáveis das empresas implica diretamente em uma queda do imposto devido.

No sentido de definirem as empresas que teriam possibilidade de se beneficiarem dos efeitos do hedge em sua tributação, os pesquisadores consideraram que economias da ordem de $+0,5 \%$ do valor do imposto devido permitiriam afirmar que a função tributação da empresa é convexa. Isso permitiu se encontrarem 55.059 empresas com funções convexas de tributação e, portanto, com possibilidade de pagar menos imposto a partir da redução na volatilidade dos lucros, em uma amostra total de 84.200 companhias.

Como resultado da pesquisa verificaram que para $99 \%$ das empresas com funções convexas de tributação existe um grande potencial de redução no valor do pagamento de imposto sobre o lucro tributável a partir da redução da volatilidade dos lucros dessas empresas. ${ }^{2}$

Assim sendo, os resultados obtidos por esses pesquisadores vão servir de valores de comparação com os resultados obtidos nesta pesquisa.

No Brasil as empresas apresentam as mesmas motivações para fazer hedge que as empresas do exterior. O principal objetivo é a proteção contra oscilações da taxa de câmbio, dos juros e dos preços das commodities. Nos Estados Unidos, especialmente, fazer hedge pode trazer um benefício adicional, pois permite que empresas possam se alavancar, sem incorrer em aumento de suas taxas de financiamento e, ainda, pagarem menos imposto de renda, pois podem abater as despesas financeiras do lucro tributável. Esta não é a realidade brasileira em que as empresas pouco se alavancam em vista da instabilidade macro-econômica apresentada pelo país.

A respeito do sistema tributário brasileiro, uma de suas características é que a taxa de tributação sobre o lucro é igual para todos os níveis de lucro possíveis de serem obtidos pelas empresas. Assim, caso a empresa tenha tido lucro em um ano e prejuízo no ano seguinte ela terá pago mais imposto de renda do que se tivesse alcançado um lucro médio nos dois anos. Além disso, a legislação brasileira não permite que se desconte todo o prejuízo acumulado de anos anteriores em um só ano, o que diminui a possibilidade de amortizar o valor de imposto a ser pago em anos nos quais a empresa tenha alcançado um lucro muito elevado, mesmo que em períodos anteriores esta mesma empresa tenha apresentado pesados prejuízos.

Dessa forma, neste artigo procurou-se analisar a situação vivenciada pelas empresas brasileiras nos anos de 2002 e 2003, que apresentaram elevada volatilidade no câmbio e nos juros, provocando, com isso, grande impacto nos resultados das empresas com dividas em dólares ou referenciadas à taxa Selic. Pôde-se verificar que algumas empresas tiveram prejuízo em 2002 por causa da variação cambial e dos juros e no ano seguinte tiveram um elevado lucro pela desvalorização cambial e queda dos juros sem que seus resultados operacionais tivessem se alterado significativamente. Buscou-se verificar se existiu vantagem no fato de as empresas brasileiras terem feito hedge para diminuir a volatilidade de seus lucros nos anos de 2002 e 2003 e se, com isso, pagaram menos imposto de renda.

Espera-se que empresas com maiores ativos e maior endividamento, que sejam mais eficientes e com maior participação do resultado financeiro nos lucros, sejam empresas que paguem mais imposto de renda e, por isso, tenham maior propensão a fazer hedge para diminuir o valor do imposto de renda a pagar. Portanto, dessa maneira procurou-se adequar os conhecimentos existentes sobre política e hedge e vantagem tributária para a realidade brasileira.

Assim, pode-se mencionar que o objetivo do trabalho é responder à seguinte questão: "Pode-se comprovar que em situações com grande volatilidade no câmbio e juros e, conseqüente alternância de lucro e prejuízo nas empresas, o fato de fazer hedge resulta em menor valor de imposto de renda a pagar?"

Nesse ponto, iniciou-se uma revisão das disposições relacionadas à legislação tributária vigente de modo que esses conceitos sirvam de base para a construção de uma simulação teórica que relacione hedge e imposto de renda a pagar.

\section{Tributos sobre o lucro das empresas}

O conhecimento da forma de tributação incidente sobre o lucro das empresas é uma questão focal nesta pesquisa. Para isso, foram verificados, a seguir, os principais postulados que orientam o

${ }^{2}$ Os valores correspondentes a essas afirmações podem ser encontrados na Tabela I, painéis A e B, que compõem os anexos do artigo "Tax incentives to hedge" de Graham, 
cálculo dos tributos incidentes sobre os lucros das companhias. Dessa forma, não serão considerados os demais impostos e contribuições existentes e aplicáveis.

Um desses tributos é o imposto de renda das pessoas jurídicas que é devido à medida que os rendimentos, ganhos e lucros forem sendo auferidos.

São duas as formas de tributação da renda da pessoa jurídica no Brasil:

I) Imposto incidente sobre o lucro real (o lucro líquido do período) - a base de cálculo é ajustada pelas adições, exclusões ou compensações prescritas. Deve se observar que toda pessoa jurídica tributada com base no lucro real tem a obrigação de elaborar seu balancete mensal para que se defina seu lucro do período, de forma que se possa utilizar essa base de cálculo para se avaliar o valor de I. R. devido.

II) Imposto incidente sobre o lucro presumido - é calculado a partir de uma estimativa de renda futura a ser auferida. Essa espécie de tributação é uma opção que a lei concede a pequenos contribuintes. Como seus negócios são de pequeno valor econômico eles podem optar pelo pagamento de imposto de renda sobre o lucro presumido. Essa modalidade não se aplica às Sociedades Anônimas que são o foco sobre o qual se apóiam as pesquisas com as quais se busca testar a existência de vantagem tributária ao se fazer hedge.

Para a Secretaria da Receita Federal, o lucro líquido do exercício calculado com base na lei comercial (Lei 6.404/76) é o elemento inicial para se definir a base de cálculo do tributo. O lucro líquido é a referência sobre a qual são adicionados e excluídos alguns valores no sentido de se obter o lucro real, que é o núcleo da base de cálculo do imposto de renda da pessoa jurídica.

É comum existirem algumas diferenças entre o lucro contábil e o lucro tributável das empresas. São exemplos disso algumas deduções permitidas pela contabilidade comercial que não são consentidas pela lei tributária. Dessa forma, esses valores são adicionados ao lucro líquido para, então, se obter o lucro real (fiscal). Uma das deduções permitidas pela legislação tributária é o abatimento dos prejuízos ocorridos em exercícios anteriores.

Existe outra tributação incidente sobre o lucro das empresas que é a Contribuição Social Sobre o Lucro (CSSL) instituída pelo Governo Federal, pela Lei $7.689 / 88$, para o financiamento da seguridade social.
A base de cálculo da contribuição, definida inicialmente pelo artigo $2^{\circ}$ da Lei 8.034/90, é o valor do resultado do exercício social encerrado em 31 de dezembro de cada ano, antes da provisão para o imposto sobre a renda. Em outras palavras a base de cálculo é o Lucro Antes do Imposto de Renda (LAIR).

Também sobre a CSSL pode incidir abatimento da parcela decorrente de prejuízos fiscais ocorridos em anos anteriores. Assim sendo, o estudo relativo aos prejuízos fiscais se torna importante, pois ele vai definir a base de cálculo a ser exposta à tributação e, portanto, vai ser vital no valor dos impostos a serem pagos pelas empresas.

\section{A questão dos prejuízos fiscais a compensar}

O artigo 189 da Lei 6.404/76 prevê que antes de apurar o lucro líquido do período (e, portanto, gerar nova base de cálculo para o imposto de renda) a sociedade tem que deduzir os prejuízos ocorridos nos exercícios anteriores.

Assim, apurado o prejuízo em exercício anterior, esse valor passa a se constituir em crédito a ser utilizado pela companhia, podendo ser utilizado no exercício seguinte em que houver lucro a compensar.

Até a edição da Medida Provisória 812/94, o direito à compensação era pleno, podendo a empresa cancelar o lucro de um período com o valor dos prejuízos acumulados anteriores. A Lei $n^{\circ} 8.891 / 95$ de conversão de tal medida provisória alterou essa disposição relacionada ao direito de compensar. Em seu artigo 42, determina que:

A partir de $1^{\circ}$ de janeiro de 1995 , para efeito de determinar o lucro real, o lucro líquido ajustado pelas adições e exclusões previstas pela legislação do imposto de renda poderá ser reduzida em, no máximo, trinta por cento.

Parágrafo único - A parcela dos prejuízos fiscais apurados até 31 de dezembro de 1994, não compensada em razão do disposto no caput deste artigo poderá ser utilizada nos anos calendários subseqüentes.

Essa mesma redação foi mantida na regulamentação expedida pela Instrução Normativa SRF $n^{\circ} 51 / 95$, de 31 de outubro de 1995, posteriormente reforçada pela Lei 9.065/95 e Instrução Normativa SRF $n^{\circ} 11 / 96$.

Existe, ainda, uma limitação relativa à compensação de prejuízos fiscais pelas empresas. A Lei 9.249/95 altera as condições relacionadas à compensação de prejuízos fiscais. Assim, os prejuízos não operacionais apurados pelas pessoas jurídicas a partir de $1^{\circ}$ de janeiro de 1996, somente podem 
ser compensados com lucros da mesma natureza, até o limite de $30 \%$, previsto no artigo 15 da Lei 9.065/95.

Nesta pesquisa não se terão condições de estudar os efeitos que essa limitação impõe às companhias abertas que servirão de base para a amostra a ser pesquisada. Contudo, entende-se oportuno evidenciar, a seguir, o resumo das novas medidas conforme os dados contidos na Tabela 2 mostrada a seguir.

Portanto, verifica-se um efeito prático dessa nova regulamentação que é o estabelecimento de uma base de cálculo mínima para o lucro tributável, no momento da determinação do imposto de renda, ocorrida em função da fixação de um limite máximo de redução do lucro tributável pelos prejuízos fiscais apurados em exercícios fiscais anteriores.

Em outras palavras, as pessoas jurídicas que detenham estoque de prejuízos fiscais apurados em anos anteriores passam a sujeitar-se a um imposto de renda mínimo, uma vez que o lucro tributável só pode ser reduzido em no máximo trinta por cento.

Os prejuízos fiscais, também, podem ser utilizados como dedução da CSSL a partir de certos ajustes indicados no artigo $7^{\circ}$ da Instrução Normativa expedida pela Secretaria da Receita Federal n 90/92.

Pelo artigo 44 da Lei $n^{\circ} 8.383 / 91$, as empresas tributadas pelo lucro real passaram a poder compensar, de um período base de apuração para o seguinte, a base de cálculo negativa, ou seja, o pre- juízo apurado no período. Tal dispositivo legal assegurava a compensação total dos prejuízos apurados com o lucro dos períodos subseqüentes, conforme se transcreve a seguir:

Artigo 44 - Aplicam-se à contribuição social sobre o lucro (Lei 7.689/88) e ao imposto incidente na fonte sobre o lucro líquido (artigo $15 \mathrm{da}$ Lei 7.713/88) as mesmas normas de pagamento estabelecidas para o imposto de renda das pessoas jurídicas.

Parágrafo único - Tratando-se de base de cálculo de contribuição social (Lei 7.689/88) e quando dela resultar negativa em um mês, esse valor, corrigido monetariamente, poderá ser deduzido da base de cálculo do mês subseqüente, no caso de pessoa jurídica tributada com base no lucro real.

A Lei 8.981/95 não somente alterou a compensação de prejuízos fiscais para efeitos de imposto de renda, afetando a base cálculo do lucro tributável, como também limitou a compensação de prejuízos fiscais até o máximo de $30 \%$ do lucro anual tributável para fins de cálculo da CSSL (artigo 58).

\section{A questão das alíquotas}

Antes de se evidenciarem as alíquotas praticadas, faz-se necessária uma breve exposição sobre o assunto. ${ }^{4}$

Tabela 2 - Dados sobre os prejuízos fiscais a compensar

\begin{tabular}{lccc} 
& Até 1994 & MP 812/94 & Lei 9.249/95 \\
$\begin{array}{l}\text { Lucro sujeito } \\
\text { à compensação }\end{array}$ & $100 \%$ & $30 \%$ & $30 \%$ \\
\hline $\begin{array}{l}\text { Período de } \\
\text { compensação }\end{array}$ & $\begin{array}{c}\text { Até 1992 e de 1993 a 1994 - 4 anos; } \\
\text { Em 1992 - prazo inderteminado }\end{array}$ & $\begin{array}{c}\text { Prazo } \\
\text { indeterminado }\end{array}$ & $\begin{array}{c}\text { Prazo } \\
\text { indeterminado }\end{array}$ \\
\hline Natureza do lucro & $\begin{array}{c}\text { Lucro operacional e } \\
\text { não operacional }\end{array}$ & $\begin{array}{c}\text { Lucro operacional } \\
\text { e não operacional }\end{array}$ & $\begin{array}{c}\text { O prejuízo não } \\
\text { operacional é } \\
\text { compensável só } \\
\text { com o lucro não } \\
\text { operacional }\end{array}$ \\
\hline
\end{tabular}

Fonte: Hiromi e Hirochi (1997).

${ }^{3}$ O prejuízo operacional é compensável com lucro operacional ou não operacional conforme artigo 15 da Lei 9.065/95.

${ }^{4}$ As informações foram obtidas no livro de Hiromi e Hirochi. 
Assim, inicialmente, pode-se mencionar que existem duas grandes divisões a respeito da tributação da renda das empresas. Um grupo significativo de empresas (as de maior porte econômico) opta pelo pagamento do imposto de renda utilizando como base para tal tributação o cálculo do lucro real. Outro grupo de empresas se utiliza da prerrogativa de pagar imposto tendo por base de cálculo o lucro presumido (a maioria das pequenas empresas opta por essa alternativa).

As empresas que se enquadram em qualquer dos incisos do artigo 36 da Lei 8.981/95, alteradas pelas Leis 9.065/95, 9.249/95 e 9.430/96 são obrigadas a apresentar declaração com base no lucro real. A opção pelo lucro presumido só é possível para as empresas que não se enquadram em nenhum dos impedimentos relacionados no artigo 36 da Lei 8.981/95, alterado pelo artigo $1^{\circ}$ da Lei 9.065/95, pelo artigo 36 da lei 9.249/95 e pelo artigo 58 da lei 9.430/96.

Além do imposto de renda, as empresas que se utilizam da base do lucro real para calcular seu imposto de renda têm outro tributo incidente sobre - lucro que é a contribuição social sobre o lucro. As empresas que optam pela tributação com base no lucro presumido pagam sua contribuição social com base na receita bruta.

Assim sendo, relacionam-se as alíquotas de impostos incidentes sobre os lucros das empresas na Tabela 3 a seguir:

\section{Tabela 3 - Dados sobre alíquotas} de I.R. e C.S.S.L.

\begin{tabular}{lcc} 
& Lucro Real & Lucro Presumido \\
I. R. & $15,00 \%+10,00 \%^{*}$ & $15,00 \%^{\star \star *}$ \\
\hline C.S.S.L. & $8,00 \%{ }^{\star \star *}$ & $12,00 \%{ }^{\star \star \star \star}$ \\
\hline Total & $33,00 \%$ & $27,00 \%$ \\
\hline
\end{tabular}

Fonte: Hiromi e Hirochi (1997).

* existe um adicional de $10 \%$ a ser pago sobre a parcela do lucro que exceder a $\mathrm{R} \$ 20.000,00$.

** o percentual adicional de $10 \%$ incide para uma pequena minoria de empresas não devendo por isso ser considerado.

*** alíquota fixada pelo artigo 19 da Lei 9.249/95.

**** alíquota incidente sobre a receita bruta.
Contudo, existem, ainda, outros impostos ou tributos incidentes sobre as operações realizadas pelas companhias abertas como PIS, COFINS, INSS, FGTS, ISS e ICMS.

Um estudo simulado da tributação percebida pelo universo de empresas abertas promovido pela FEA/USP e FIPECAFI (1998) ${ }^{5}$ evidencia que essas organizações tiveram alíquotas de tributação variável entre 15,0\% e 40,0\% nos anos de 1997 e 1998.

Dessa forma, para efeito de cálculos nessa simulação envolvendo hedge e valor do imposto de renda a pagar, será utilizado o valor de 30,0\% para a alíquota média.

\section{METODOLOGIA UTILIZADA}

Esta pesquisa se insere na linha epistemológica néo-positivista em que se procura construir um referencial teórico que permita compreender o fenômeno estudado e, além disso, buscar evidências empíricas que comprovem as expectativas.

No sentido de conseguir chegar ao objetivo final, promoveu-se uma pesquisa secundária documental e telematizada, para conseguir uma base de dados que permitisse a aplicação de método estatístico de análise. Utilizaram-se as demonstrações das empresas para conseguir saber se tinham política de hedge e se evidenciavam os resultados financeiros obtidos com as práticas de hedge nos anos de 2002 e 2003. Depois, usou-se a Economática para reunir os dados referentes às empresas da amostra.

O universo de pesquisa compreendeu as companhias abertas brasileiras. Dentro desse universo buscou-se uma amostra de empresas que tenham tido lucro em 2003 e prejuízo em 2002, que tenham feito hedge nesses anos e evidenciado os resultados do hedge em suas demonstrações financeiras. Em seguida selecionou-se um conjunto de variáveis que pudessem contribuir para o estudo. Dessa forma, chegou-se a um total de 24 empresas e um conjunto de 11 variáveis sendo 2 dependentes e 9 independentes.

Nesse conjunto de variáveis independentes incluiu-se 4 variáveis de controle. Uma para tamanho (logaritmo do ativo total), uma para eficiência de geração de lucro (LAIR / Lucro Bruto), uma para participação do resultado financeiro no lucro (Resultado financeiro/Lucro Bruto) e uma para o nível de endividamento (Dívida Total/ Ativo Total).

Por último, os dados da amostra foram inseridos em uma análise estatística que utilizou como

\footnotetext{
${ }^{5}$ O estudo é denominado "Sistema financeiro e crescimento econômico" realizado por Rocca, C. A. \& Carvalho, A. G., \& Silva, M. E. e está contido no livro "Soluções para o mercado de capitais brasileiro", Rio de Janeiro, José Olympio Editora, 2001, 175 pág.
} 
método o uso de regressões lineares múltiplas que possibilitassem verificar a existência de uma relação estatística significativa entre as variáveis em estudo.

\section{SIMULAÇÃO TEÓRICA}

Tendo em vista o propósito deste estudo - verificar se existem benefícios fiscais advindos de se fazer hedge em situações de alta volatilidade das taxas de câmbio e de juros que provoquem fortes impactos nos resultados das companhias - serão focadas as empresas que possuam elevado endividamento e que seus resultados (lucros ou prejuízos) sejam fortemente correlacionados ao desempenho de sua gestão financeira. Dessa forma, tais companhias permanecem com maior freqüência na região onde há descontinuidade da alíquota referente à tributação, conforme se pode verificar no Gráfico 2 mostrado a seguir:

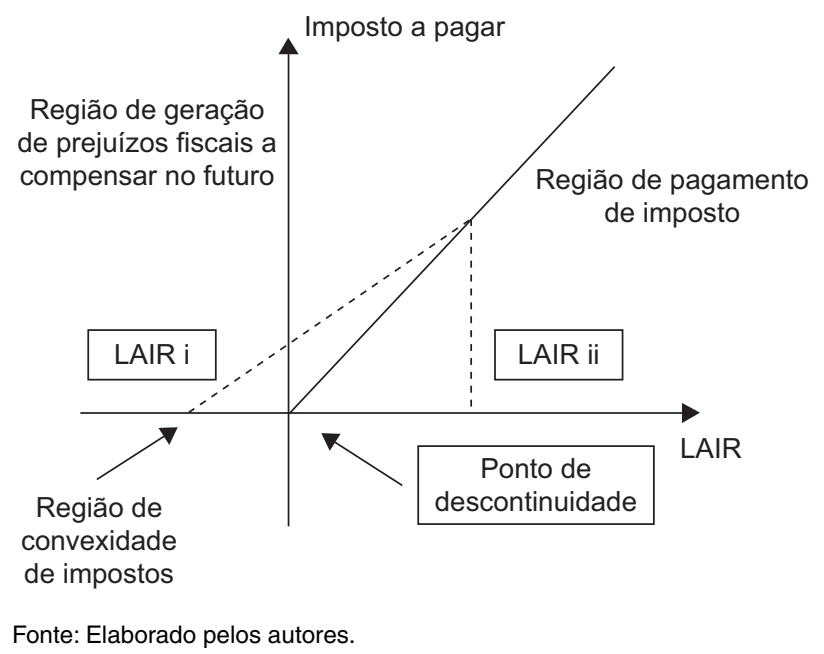

\section{Gráfico 2 - Regiões de tributação}

Na região de convexidade, pode-se observar, por meio da utilização do teorema de Jensen, que a média dos valores dos tributos $A$ e $B$ referentes a dois exercícios sociais consecutivos é maior que o valor médio de tributos que incidiria caso a empresa tivesse tido um lucro médio nos dois exercícios.

Dessa forma, a empresa ao diminuir sua volatilidade teria conseguido diminuir significativamente sua carga tributária. O Gráfico 3 , a seguir, explicita a vantagem a ser conseguida pela empresa ao longo de dois exercícios em que tenha tido grande prejuízo e posteriormente grande lucro ou vice-versa.

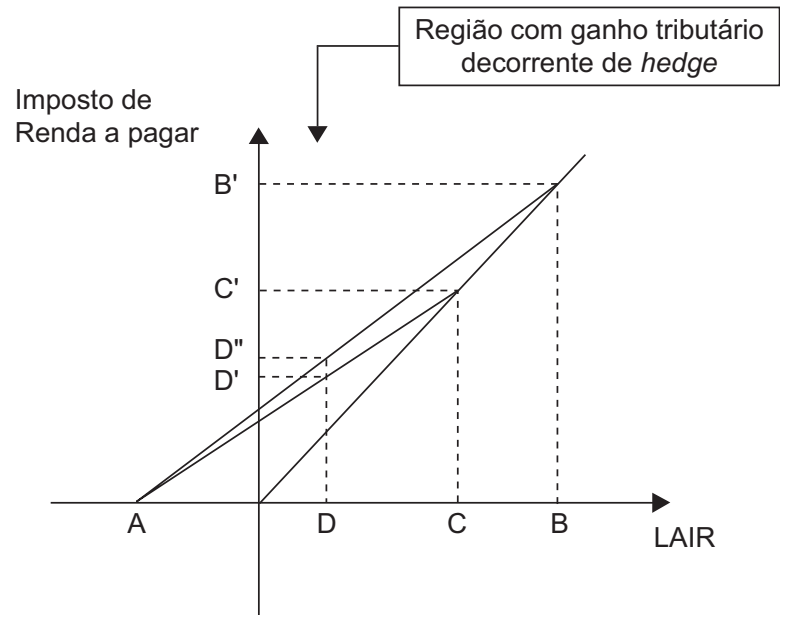

Fonte: Elaborado pelos autores.

\section{Gráfico 3 - Regiões com ganho tributário}

Em que:

A - valor negativo do LAIR no ano 1 (valor a ser agregado aos prejuízos fiscais a serem compensados pela empresa no futuro);

B - valor do LAIR no ano 2, caso a empresa não possa compensar nenhum prejuízo fiscal (em outras palavras é o valor a servir de base para o pagamento de imposto por uma empresa que não tenha prejuízos fiscais anteriores);

C - valor do LAIR do ano 2, caso a empresa tenha prejuízos fiscais a serem compensados;

D - valor do LAIR médio que a empresa pode obter caso tenha feito hedge para um lucro médio no período;

B'- valor do imposto devido para o valor do LAIR de B;

C'- valor do imposto devido para o valor do LAIR de C;

D'- valor do imposto devido para o valor do LAIR de $D$ no caso de a empresa ter prejuízos fiscais a compensar;

D"- valor do imposto devido para o valor do LAIR de $D$ no caso de a empresa não ter prejuízos fiscais a compensar;

Da observação do Gráfico 3, pode-se concluir que, em situações com dois exercícios sociais de resultados muito diferentes, ou seja, um exercício com lucro e outro com prejuízo, sempre é mais vantajoso se fazer o hedge para obter um lucro médio, tendo um incentivo significativo de não pagamento de imposto desde que o valor do LAIR positivo seja maior em módulo que o LAIR negativo e que a empresa somente possa compensar pequena parte de seu(s) prejuízo(s) fiscal(is) de exercício(s) anterior(es). 
Essa evidência pode ser verificada no gráfico anterior, pois D' (imposto devido quando a empresa tem prejuízos fiscais a compensar) ou D" (imposto quando a empresa não tem prejuízos fiscais a compensar) é sempre um valor menor que B' ou C', satisfeita a exigência de que $|\mathrm{B}|>|\mathrm{A}|$. Caso contrário, o valor médio de imposto a pagar pode cair em uma região de geração de prejuízos fiscais a compensar no futuro.

Para enfatizar-se esse raciocínio, recorre-se aos resultados da comparação entre uma empresa na situação I, com lucros médios estimados em 25 e na situação II na qual a mesma empresa alterna lucros de 150 com prejuízos de 100, a cada dois anos.

Assim, tomando o exemplo mencionado, a cada período de dois anos a empresa sentiria a seguinte diferença, conforme se pode evidenciar na Tabela 4:

Situação a cada dois anos:

\section{Tabela 4 - Simulação das tributações das empresas}

\begin{tabular}{lccccc} 
Situação I & I.R. & LAIR & Situação II & I.R. & LAIR \\
Ano 1 & $7,5^{\star}$ & 25,0 & Ano 1 & 0 & $(100,0)$ \\
\hline Ano 2 & $7,5^{\star}$ & 25,0 & Ano 2 & $36,0^{\star \star}$ & 150,0 \\
\hline Total & 15,0 & 50,0 & Total & 36,0 & 50,0 \\
\hline
\end{tabular}

Fonte: Elaborado pelos autores.

Valores de IR:

*I.R. $=30 \% \times 25 \times 2=15,0$

**I.R. $=30 \% \times(150-(30 \% \times 100))=36,0$

$\Delta \mathrm{I} . \mathrm{R} .=36,0-15,0=21,0$

Valores dos Lucros Líquidos para as 2 situações:

$\Sigma$ L.Liq. (Situação I) $=$ LAIR ano $1+$ LAIR ano $2-$ I.R. (total $)=$

$25,0+25,0-15,0=35,0$

$\Sigma$ L.Liq. $($ Situação II $)=$ LAIR ano $1+$ LAIR ano $2-$ I.R. (total) $=$

$-100,0+150,0-36,0=14,0$

$\Delta$ L.Liq $=\Delta$ I.R. $=35,0-14,0=21,0$

Portanto, pode-se verificar que:

$\Delta$ L.Liq $=\Delta$ I.R. $=21,0$

Percebe-se que, no exemplo em questão, a empresa deixa de pagar um valor de imposto que se reflete em parcela de lucro a ser apropriado ao resultado da empresa no período dos dois anos.

Daí se conclui que se a empresa acredita que vai passar por um período de grande turbulência em seus resultados, a política de hedge pode significar um grande acréscimo de valor ao seu lucro líquido agregado.

\section{BUSCANDO EVIDÊNCIAS EMPÍRICAS}

Para se promover uma verificação da teoria apresentada, escolheu-se o período de 2002 - 2003 para coletar dados de empresas que tenham optado por fazer hedge cambial ou de taxas de juros para suas dívidas. Nesse período, a grande instabilidade política provocou diversos efeitos econômicos e financeiros. Assim, tanto a taxa de câmbio quanto as taxas de juros subiram muito em relação ao restante do ano de 2002. Contudo, depois de passada a turbulência relativa ao processo de eleição presidencial, tanto a taxa de câmbio quanto as taxas de juros voltaram a seus patamares anteriores à crise. Esse movimento de taxas de câmbio e de juros alterou, sobremaneira, os resultados das companhias, especialmente as que tinham dívidas elevadas.

Assim sendo, para completar a análise dos efeitos do hedge nos resultados obtidos pelas empresas nos anos de 2002 e 2003 e, por conseguinte, no valor do imposto de renda a pagar, procurouse selecionar companhias abertas brasileiras que indicassem se tinham ou não política de hedge e que evidenciassem em suas notas explicativas o resultado líquido das operações de hedge obtido nos dois anos mencionados (2002-2003), em meio a uma amostra contendo as 500 maiores empresas nacionais pelo critério de vendas brutas que foi coletada na Economática.

Dessa forma, encontraram-se as seguintes 24 companhias abertas:

AES Elpa, Ambev, Brasil Telecom, Bunge Brasil, Caraíba Metais, CSN, Embraco, Embraer, Embratel, Fosfértil, Gerdau, Klabin, Net, Perdigão, Petrobrás, Sadia, Tele Sudeste Celular, Telefônica, Telemar, Telemar Norte Leste Participações, Tractabel, Usiminas, Vale do Rio Doce, Votorantim Papel e Celulose.

Foram retirados os valores finais das operações com hedge em 2002 e 2003, conforme já mencionado, além do valor do imposto de renda em 2003 e o valor dos lucros / prejuízos acumulados em 2002. A respeito dos valores da última rubrica mencionada pode-se salientar que os saldos de prejuízos acumulados apenas eram significativos em três empresas - AES Elpa, Net e Telefônica.

Com o objetivo de verificar a influência do hedge na diminuição da carga tributária para diferentes tipos de empresas utilizou-se como variáveis de controle o tamanho da empresa (medido pelo logaritmo do Ativo Total em $\mathrm{R} \$$ milhões), a razão percentual (LAIR/Lucro Bruto) $\times 100 \%$, a razão percentual $(\mathrm{Re}-$ sultado Financeiro/Lucro bruto) $\times 100 \%$ e a razão percentual (Endividamento/Lucro bruto) $\times 100 \%$.

As variáveis mencionadas controlam: 
- os resultados para diferentes tamanhos de empresas;

- os resultados para empresas com grande diferença de eficiência em gerar LAIR a partir do Lucro Bruto;

- os resultados para empresas com diferentes participações do resultado financeiro no LAIR;

- os resultados para empresas com diferentes níveis de endividamento.

Pressupondo a independência das variáveis, testou-se a existência de correlações estatísticas entre essas variáveis através de uma regressão linear múltipla utilizando o software SPSS 11.5. As fórmulas das regressões que serão testadas são do tipo:
As variáveis utilizadas foram:

- IR 2003 - é a variável explicada. Representa o valor do imposto de renda contabilizado nas demonstrações financeiras das companhias da amostra em 2003.

- IR 2002 - representa o valor do imposto de renda contabilizado nas demonstrações financeiras das companhias da amostra em 2002. Utilizou-se essa variável como uma proxy para correlacionar com o valor do IR 2003, características como regularidade e efetividade do pagamento de imposto. Espera-se que o coeficiente dessa variável seja positivo demonstrando que empresas que têm um histórico de pagamento regular de imposto de renda têm

$\mathrm{IR} 2003=\mathrm{A}+\mathrm{B} \times \mathrm{IR} 2002+\mathrm{C} \times H E D G E 2003+\mathrm{D} \times H E D G E 2002+\mathrm{E} \times \mathrm{PREJ}$ ACUM $2002+\mathrm{F} \times$

$\log \mathrm{AT}+\mathrm{G} \times(\mathrm{LAIR} / \mathrm{LB})+\mathrm{H} \times($ Res Fin/LB $)+\mathrm{I} \times($ Endividamento/AT $)$.

IR Méd $20032002=\mathrm{A} 1+\mathrm{B} 1 \times H E D G E 2003+\mathrm{C} 1 \times H E D G E 2002+\mathrm{D} 1 \times$ PREJ ACUM $2001+\mathrm{E} 1 \times$

$\log \mathrm{AT}+\mathrm{F} 1 \times(\mathrm{LAIR} / \mathrm{LB})+\mathrm{G} 1 \times($ Res Fin/LB $)+\mathrm{H} 1 \times($ Endividamento/AT $)$.

uma probabilidade maior de continuar pagando imposto.

- IR Méd 2003/2002 - representa a média aritmética dos valores de imposto de renda pagos pelas empresas no período de 2002 e 2003.

- HEDGE 2002 - representa o valor líquido das operações com hedge contabilizado em 2002, evidenciado nas notas explicativas das demonstrações financeiras das companhias. Espera-se que o coeficiente dessa variável seja negativo e que as empresas que se utilizaram de hedge em 2002 tenham reduzido o valor de seu imposto a pagar.

- HEDGE 2003 - representa o valor líquido das operações com hedge contabilizado em 2003, evidenciado nas notas explicativas das demonstrações financeiras das companhias. Espera-se que o coeficiente dessa variável seja negativo e que as empresas que se utilizaram de hedge em 2003 tenham reduzido o valor de seu imposto a pagar.

- PREJ ACUM 2002 - representa o valor dos prejuízos acumulados em 2002 e contabilizados nas demonstrações financeiras das companhias. A expectativa é que o sinal do coeficiente dessa variável seja negativo em vista de se esperar que empresas que tenham prejuízos acumulados em exercícios fiscais anteriores paguem menos imposto de renda que as demais.

- PREJ ACUM 2001 - representa o valor do prejuízo acumulado existente em 2001. A expectativa é de que seja negativamente relacionado com o valor do imposto de renda médio pago pelas empresas.

- Logaritmo do Ativo Total (Log AT) - representa o logaritmo do Ativo Total das empresas. Espera-se que esta variável esteja positivamente relacionada com a variável dependente.

- LAIR/LB (LAIR/LB) - representa a razão percentual entre o LAIR e o Lucro Bruto e identifica quanto é o percentual do Lucro Bruto gerado pela empresa que chega a ser lucro tributável. Espera-se que esta variável seja positivamente relacionada com a variável dependente, pois quanto maior o LAIR maior o imposto de renda a ser pago pela companhia.

- Resultado Financeiro/LB (Res Fin/LB) - representa o percentual do resultado financeiro gerado pela companhia. Espera-se que esta variável seja positivamente relacionada 
com a variável dependente, pois quanto maior for o resultado financeiro maior será o lucro bruto e maior o imposto a pagar.

- Endividamento/LB (Debt/AT) - representa o percentual de endividamento que a empresa apresenta. Espera-se que esta variável seja negativamente relacionada com a variável dependente, pois quanto maior o endividamento maior a probabilidade de a empresa comprometer boa parte dos seus lucros com o pagamento de juros e assim diminuir os lucros tributáveis e o imposto de renda a ser pago.

\section{Tabela 5 - Resultados da regressão Variável dependente - IR 2003}

\begin{tabular}{|c|c|c|}
\hline & $\begin{array}{c}\text { Modelo com } \\
\text { todas as } \\
\text { variáveis }\end{array}$ & Modelo otimizado \\
\hline Constante & $\begin{array}{c}-0,762 \text { * } \\
(0,100)\end{array}$ & $\begin{array}{c}-0,799 \text { ** } \\
(0,040)\end{array}$ \\
\hline Hedge 2003 & $\begin{array}{r}-0,607 \\
(0,102)\end{array}$ & $\begin{array}{c}-0,609 \text { * } \\
(0,098)\end{array}$ \\
\hline Hedge 2002 & $\begin{array}{c}-0,975^{\star \star} \\
(0,032)\end{array}$ & $\begin{array}{c}-1,001 \text { ** } \\
(0,011)\end{array}$ \\
\hline IR 2002 & $\begin{array}{l}0,878^{\star \star *} \\
(0,001)\end{array}$ & $\begin{array}{l}0,866^{* \star *} \\
(0,000)\end{array}$ \\
\hline Prej Acum 2002 & $\begin{array}{c}-0,387^{\star * *} \\
(0,000)\end{array}$ & $\begin{array}{c}-0,386 \text { *** } \\
(0,000)\end{array}$ \\
\hline Log AT & $\begin{array}{l}1,153^{\star * \star} \\
(0,004)\end{array}$ & $\begin{array}{l}1,110 \text { *** } \\
(0,002)\end{array}$ \\
\hline LAIR/LB & $\begin{array}{c}0,453 \\
(0,364)\end{array}$ & $\begin{array}{c}0,574 \\
(0,146)\end{array}$ \\
\hline Res Fin/LB & $\begin{array}{c}0,311 \\
(0,640)\end{array}$ & - \\
\hline Debt/AT & $\begin{array}{r}-0,016 \\
(0,985)\end{array}$ & 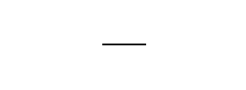 \\
\hline $\mathrm{R}^{2}$ & 0,933 & 0,932 \\
\hline $\mathrm{R}^{2}$ ajustado & 0,898 & 0,909 \\
\hline $\mathrm{F}$ & $\begin{array}{c}26,314^{* * *} \\
(0,000)\end{array}$ & $\begin{array}{c}39,122 \text { *** } \\
(0,000)\end{array}$ \\
\hline
\end{tabular}

Fonte: Dados da regressão linear múltipla gerados pelo software SPSS versão 11.5 para variável dependente IR2003.

* estatisticamente significativo a $1 \%$

** estatisticamente significativo a $5 \%$

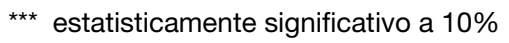

Entende-se ser significativo trabalhar apenas com valores de mesma ordem de grandeza de forma a não promover qualquer interferência nos resultados gerados. Por isso, incluíram-se os valores em $\mathrm{R} \$$ milhões de forma a possibilitar a participação de índices entre as variáveis explicadas.

Tabela 6 - Resultados da regressão Variável dependente - IR MED 20032002

\begin{tabular}{|c|c|c|}
\hline & $\begin{array}{c}\text { Modelo com } \\
\text { todas as } \\
\text { variáveis }\end{array}$ & Modelo otimizado \\
\hline Constante & $\begin{array}{r}-0,303 \\
(0,536)\end{array}$ & $\begin{array}{r}-0,362 \\
(0,234)\end{array}$ \\
\hline Hedge 2003 & $\begin{array}{r}-0,406 \\
(0,334)\end{array}$ & - \\
\hline Hedge 2002 & $\begin{array}{c}-1,4911^{\star \star \star} \\
(0,001)\end{array}$ & $\begin{array}{c}-1,211^{\text {***}} \\
(0,000)\end{array}$ \\
\hline Prej Acum 2001 & $\begin{array}{r}-0,409 \\
(0,122)\end{array}$ & $\begin{array}{c}-0,404 \text { * } \\
(0,056)\end{array}$ \\
\hline Log AT & $\begin{array}{l}0,737^{*} \\
(0,097)\end{array}$ & $\begin{array}{l}0,949 \text { *** } \\
(0,005)\end{array}$ \\
\hline LAIR/LB & $\begin{array}{r}-0,105 \\
(0,846)\end{array}$ & 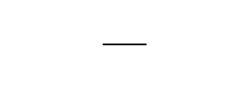 \\
\hline Res Fin/LB & $\begin{array}{c}0,174 \\
(0,814)\end{array}$ & 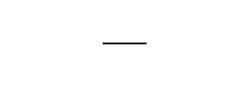 \\
\hline Debt/AT & $\begin{array}{c}0,458 \\
(0,641)\end{array}$ & - \\
\hline $\mathrm{R}^{2}$ & 0,875 & 0,865 \\
\hline $\mathrm{R}^{2}$ ajustado & 0,808 & 0,837 \\
\hline $\mathrm{F}$ & $\begin{array}{c}13,125^{\star * *} \\
(0,000)\end{array}$ & $\begin{array}{c}30,562 \text { *** } \\
(0,000)\end{array}$ \\
\hline
\end{tabular}

Fonte: Dados da regressão linear múltipla gerados pelo software SPSS versão 11.5 para variável dependente IR MED20032002.

* estatisticamente significativo a $1 \%$

** estatisticamente significativo a $5 \%$

*** estatisticamente significativo a $10 \%$

\section{ANÁLISE DOS RESULTADOS E CONCLUSÕES}

Da análise teórica dos resultados das simulações verifica-se que para empresas que oscilem em situação constante de alternância entre grandes prejuízos e lucros existe vantagem em se fazer hedge para se diminuir a carga tributária e agregar valor às empresas. 
Os efeitos do hedge nos valores de I.R. a pagar, no período de dois anos da situação teórica, foram significativos e impactaram, como a teoria previa, o valor do lucro líquido da companhia.

Em relação aos resultados da regressão testada, verificou-se, como era de se esperar, que o valor médio do hedge praticado pelas empresas em 2002 foi positivo (R\$ 102,9 Milhões) e em 2003 foi negativo (R\$ 167,1 Milhões).

Pôde-se constatar, também, que as variáveis explicativas têm forte correlação com a variável explicada na primeira regressão e baixa correlação entre si, conforme se pode verificar na Tabela 7 abaixo. Não existem correlações significativas na segunda regressão que mereçam comentários. Além disso, os modelos apresentam elevadas significâncias de predição (teste de $\mathrm{F}=39,122$ na primeira regressão e $F=30,562$ na segunda regressão) demonstrando grande eficiência.

$O$ valor de $R^{2}$ ajustado é de 0,909 na primeira regressão e 0,837 na segunda regressão, confirmando uma boa aderência da curva aos dados levantados. Verificou-se, ainda, que todos os estimadores têm baixos $p$-values na primeira regressão, confirmando as hipóteses derivadas da teoria. $\mathrm{Na}$ segunda regressão verificou-se que o hedge em 2002, o prejuízo acumulado em 2001 e o tamanho das empresas foram as variáveis de influência significativa no imposto de renda médio pago.

Dos resultados das regressões, pode-se afirmar, também, que empresas que fizeram hedge nos dois anos pesquisados diminuíram o valor do imposto de renda a ser pago em 2003, sendo que o hedge em 2002 foi significativo para a queda do valor médio de IR a ser pago. Além disso, quanto maiores os prejuízos acumulados menores são os valores de imposto de renda a ser pago. Portanto, empresas com grandes prejuízos acumulados têm menor propensão a fazer hedge para diminuir seu imposto a pagar do que empresas que não têm prejuízos acumulados em seus balanços patrimoniais. O fato é que empresas com prejuízos acumulados diminuem seus lucros tributáveis e, portanto, diminuem o valor do IR a pagar.

Tabela 7 - Tabela de correlações entre as variáveis da primeira regressão

\begin{tabular}{|c|c|c|c|c|c|c|c|c|c|c|}
\hline & & IR03 & HEDGE03 & HEDGE02 & IR 2002 & LUCAC02 & $\log A T$ & LAIRLB & RESFINLB & DEBAT \\
\hline \multirow{9}{*}{$\begin{array}{l}\text { Pearson } \\
\text { Correlation }\end{array}$} & IR 2003 & 1,000 & & & & & & & & \\
\hline & HEDGE 2003 & 346 & 1,000 & & & & & & & \\
\hline & HEDGE 2002 &,- 772 &,- 684 & 1,000 & & & & & & \\
\hline & IR 2002 &,- 071 & ,088 &,- 256 & 1,000 & & & & & \\
\hline & Prej Acum 2002 &,- 407 &,- 164 & ,080 & ,913 & 1,000 & & & & \\
\hline & $\log A T$ & ,655 &,- 190 &,- 252 &,- 347 &,- 442 & 1,000 & & & \\
\hline & LAIR / LB & ,135 & ,222 &,- 233 & ,177 & 130 &,- 137 & 1,000 & & \\
\hline & RESFIN / LB & ,090 & ,374 &,- 233 &,- 010 &,- 068 &,- 253 &, 570 & 1,000 & \\
\hline & DEB / AT &,- 132 &,- 038 & , 188 & , 177 & , 180 &,- 119 & 130 &,- 008 & 1,000 \\
\hline \multirow[t]{9}{*}{ Sig. (1-tailed) } & IR 2003 & & & & & & & & & \\
\hline & HEDGE 2003 & ,049 & & & & & & & & \\
\hline & HEDGE 2002 & ,000 & ,000 & & & & & & & \\
\hline & IR 2002 & 371 & ,342 & ,114 & & & & & & \\
\hline & Prej Acum 2002 & ,024 & ,221 & ,355 & ,000 & & & & & \\
\hline & $\log A T$ &, 000 & , 187 &, 117 & 049 & ,015 & & & & \\
\hline & LAIR / LB & ,264 & ,149 & , 136 & ,204 & ,272 & ,262 & & & \\
\hline & RESFIN / LB & ,338 & ,036 & ,137 & ,481 & ,376 & ,116 & ,002 & & \\
\hline & DEB / AT & 270 & ,430 & 190 & ,204 & 200 & 289 & ,272 & , 485 & \\
\hline
\end{tabular}

Fonte: Dados das correlações das variáveis dependentes e independentes da regressão linear múltipla para a variável dependente IR 2003. 
Por último, verificou-se que empresas com histórico de pagamento de imposto em ano anterior têm maior probabilidade de pagamento de imposto no ano subseqüente. Esse resultado pode ser confirmado, na prática, pelo fato de que empresas que possuam uma história de lucros constantes, que não tenham prejuízos acumulados nem tenham adquirido empresas com prejuízos passíveis de compensação, apresentam histórico de pagamento de imposto de renda ano após ano.

Verificou-se, também, que quanto maiores as empresas (em tamanho de seus ativos) maior o valor de imposto de renda a ser pago. Esta verificação se valida em vista de as empresas com maiores ativos serem normalmente empresas que acabam gerando maiores lucros e, portanto, maiores valores de impostos de renda a pagar.
Concluí-se, pelos resultados da simulação teórica e da regressão, que existe benefício fiscal decorrente de se fazer hedge em uma situação de elevada volatilidade de variáveis econômicas e financeiras com taxa de câmbio e de juros, conforme se pôde comprovar nos anos de 2002 e 2003. Logo, comprovou-se que, nessas situações, existe diferença no valor do imposto de renda a ser pago pelas companhias e que as que optam por políticas de hedge podem incorporar esses recursos ao valor da companhia em vez de ser pago como tributo.

Todos os resultados das investigações deste estudo são fundamentados na teoria financeira e nos estudos anteriores a respeito da influência do hedge na tributação das empresas.

\section{REFERÊNCIAS BIBLIOGRÁFICAS}

\begin{abstract}
AMMON, Norbert. Why hedge? A critical review of theory and empirical evidence. Zentrum für Europäisch Wirtschaftsforschung, working paper disponível no International Finance and Financial Management.
\end{abstract}

BARTRAM, Söhnke M.; BROWN, Gregory W.; FEHLE, Frank R.. International evidence of financial derivative usage. Site $<w w w$. ssrn.com>. Acesso: março, 2004.

BEBER, Alessandro. Laboratory of Economics and Management. Trento University, working paper, agosto, 2001.

BRAGA, Eduardo; SOUZA, Almir Ferreira de.. A utilização do contrato futuro de taxa de câmbio como instrumento de hedge em importação - um estudo de caso - VII SEMEAD - Seminários de Administração da FEA/USP, agosto de 2004.

BREALEY, R.A.; MYERS, Stewart C.; MARCUS, Alan. Fundamentals of corporate finance. McGraw-Hill Inc., 1995.

BROWN, G.. Managing foreign exchange risk with derivatives. Journal of Financial Economics 60, p. 401-448, 2001.

CHIECH, Way Hsin; ROCHA, Keyler Carvalho. Operações estruturadas com uso de derivativos. Monografia. Depto. de Administração - FEA-USP, 2002.

COMISSÃO DE VALORES MOBILIÁRIOS. Instrução CVM 371/02 e Deliberação CVM 273/98.

FERREIRA, Marilene Freire. Volume de hedge financeiro em uma empresa: Um estudo de caso. Dissertação de Mestrado da EAESP/2001.

FIGUEIREDO, Antônio Carlos. Introdução aos Derivativos. São Paulo: Pioneira Thompson Learning, 2002.

GECZY, C.; MINTON, B.; SCHRAND, C.. Why firms use currency derivatives. Journal of finance 52, p. 1323-1354, 1997.
GITMAN, L. J.. Princípios de Administração Financeira. $3{ }^{a}$ ed.. São Paulo: Harbra, 1987.

GRAHAM, John R.; ROGERS, Daniel A.. Does corporate hedging increases firm value? An empirical analysis, Janeiro/2000, site $<$ www.ssrn.com>.

; ROGERS, Daniel A.. Do firms hedge in response to tax incentives? The Journal of Finance. Vol LVII, $\mathrm{n}^{\circ} 2$, april, 2002.

; SMITH, Clifford W. Jr. Tax incentives to hedge. Site <www.ssrn.com>, Julho/1998.

GUAY, Wayne; KOTHARI, S. P.. How much do firms hedge with derivatives? Disponível no site <www.ssrn.com.br> e publicado no journal of Financial Economics em 2003.

HIGUSHI Hiromi; HIGUCHI, F. Hirochi. Imposto de renda das empresas: interpretação e prática. $27^{a}$ ed. São Paulo. Atlas, 1997.

HULL, J.. Options, futures and other derivatives. $4^{\text {a }}$ ed. N.J: Printice Hall, Englewood Cliffs, 1997.

IUDÍCIBUS, Sérgio de. Teoria da Contabilidade. $5^{\text {a }}$ ed.. São Paulo: Atlas, 1997.

JUDGE, Amrit.. Why do firms hedge? A review of the evidence. Middlesex University Business School, Londres, working paper, novembro, 2003.

LOPES, Alexsandro Broedel; LISBOA, Lázaro Plácido. Disclosure de operações com derivativos: um estudo comparativo Brasil versus Estados Unidos. São Paulo. Revista da BMF, n 124, agosto/98.

MADEIRA, Geová José. Identificação do nível de harmonização das normas contábeis brasileiras com as normas internacionais do IASB. $17^{\circ}$ Congresso Brasileiro de Contabilidade do Conselho Federal de Contabilidade. 
MANUAL DE ECONOMIA. Equipe de professores da USP. São Paulo. Editora Saraiva.

ROCCA, C.A.. Soluções para o mercado de capitais brasileiro. Rio de Janeiro: José Olympio, 2001.

ROSS, S. A., WESTERFIELD, R.W., JAFFE, J.F.. Administração Financeira: Corporate Finance. $2^{\mathrm{a}}$ ed. São Paulo: Atlas, 2002.

Site da Bovespa <www.bovespa.com.br> e da Comissão de Valores Mobiliários <www.cvm.gov.br> para obtenção das demonstrações financeiras das companhias abertas.
Site da Secretaria da Receita Federal <www.fazenda.receita.gov. br> para obtenção das instruções normativas.

SMITH, C. W., Jr., STULZ, R. M.. The determinantes of firms' hedging policies. Journal of Financial and Quantitative Analysis 20, p.391-405, 1985.

STULZ, R.. Rethinking risk managment. Journal of Applied Corporate Finance 9, p.8-24, 1996.

NOTA:

Endereço dos autores:

PUC-Rio

Rua Marquês de São Vicente, 225 - Gávea

Rio de Janeiro - RJ

22453-900 